\title{
Close-Call Counterfactuals and Belief-System Defenses: I Was Not Almost Wrong But I Was Almost Right
}

\author{
Philip E. Tetlock \\ Ohio State University
}

\begin{abstract}
Drawing on samples of professional observers of world politics, this article explores the interrelations among cognitive style, theoretical outlook, and reactions to close-call counterfactuals. Study 1 demonstrated that experts (especially high scorers on a composite measure of need for closure and simplicity) rejected close-call counterfactuals that redirected history when these counterfactuals undermined a preferred framework for understanding the past (the "I-was-not-almost-wrong" defense). Study 2 demonstrated that experts (especially high scorers on need for closure and simplicity) embraced close-call counterfactuals that redirected history when these counterfactuals protected conditional forecasts from refutation (the predicted outcome nearly occurred-so "I was almost right"). The article concludes by considering the radically different normative value spins that can be placed on willingness to entertain close-call counterfactuals.
\end{abstract}

Many scholars have commented on a curious asymmetry: People often display far greater confidence in their explanations of the past than they do in their predictions of the future (cf. Fischhoff, 1975; Tetlock \& Belkin, 1996). One influential explanation holds that people engage in retrospective data fitting when they account for known outcomes from the past, selectively searching for potential causal antecedents that make what happened appear as inevitable as can be made plausible, hence the well-replicated certainty-of-hindsight effect (Hawkins \& Hastie, 1990). But when people ponder the future, they do not yet know which of the myriad of possible outcomes will materialize and, in the absence of outcome knowledge, hedge their bets by scaling back confidence in any given future. Of course, people may not scale back as much as they should. They may still be too confident given their objective "hit-minus-false-alarm" accuracy score (cf. Fischhoff, 1982), but they do become less confident, hence the potentially paradoxical coexistence of ex post determinism and ex ante uncertainty.

This article reports a set of field studies that examine how experts in world politics cope with the dual problem of making sense of the past and of anticipating the future. Given the multiplicity of potential causes and interactions, our working assumption is that both tasks are far beyond the computational capacity of any human being (cf. Tetlock, 1998). Accordingly, experts

This research was supported by funds from the Institute on Global Conflict and Cooperation of the University of California, the Mershon Center of Ohio State University, and the MacArthur Foundation.

I acknowledge the advice and assistance of Aaron Belkin, Richard Boettger, Terry Busch, Beth Elson, Richard Herrmann, Charles McGuire, Gregory Mitchell, Anthony Tyler, Ned Lebow, and Geoffrey Parker. I also offer special thanks to Daniel Kahneman for his insightful advice at several junctures in the unfolding of this decade-long project.

Correspondence concerning this article should be addressed to Philip E. Tetlock, Department of Psychology, Ohio State University, 1885 Neil Avenue, 142 Townshend, Columbus, Ohio 43210 . Electronic mail may be sent to tetlock.1@osu.edu. resort to well-known simplifying strategies. Looking backward in time, they impose explanatory schemata that, like Hempel's (1965) covering laws, depict what happened as the inexorably logical result of abstract causal forces operating on well-defined antecedent conditions. For example, one influential, although by no means universally accepted, explanatory schema in world politics is neorealist balancing: When one state threatens to become too powerful and capable of dominating the entire international system, other states - rational, self-preserving actors as they are posited to be-coalesce against it, thereby preserving the balance of power (cf. Layne, 1993; Vasquez, 1997; Waltz, 1979). From this standpoint, it is no accident that wouldbe world conquerors, such as Philip II, Napoleon, or Hitler, failed. Their failure was predetermined by a fundamental law of world politics. Looking forward in time, these experts should use the same explanatory schema to generate predictions. Even though the United States has emerged as the only global superpower at the 20th century's end, this hegemony will be but brief (Layne, 1993) as other states quickly acquire the economic, technological, and military means to assert their autonomy in what remains (idealistic rhetoric notwithstanding) an anarchic international environment. Soon one should expect the emergence of nuclear-armed challengers-although the theory is neutral on the national identities of these challengers (a Germanled Europe, an irredentist Russia, a resurgent China or Japan, an Islamic super-state, etc.) and vague on issues of timing.

Although all humans must resort to simplifying strategies to cope with world politics, it does not follow that they are equally predisposed to do so. There are well-documented individual differences among scientists in the value they place on parsimony in choosing among rival theories (cf. Feist, 1994). There are also extensively studied individual differences in cognitive styles, and this research program focuses on two of them: Kruglanski and Webster's (1996) work on need for closure and the work of Suedfeld $(1983,1992)$ and Tetiock $(1988,1992 a)$ on integrative complexity. Theoretically, high need-for-closure individuals are characterized by two tendencies: urgency which in- 
clines them to "seize" quickly on readily available explanations and to dismiss alternatives and permanence which inclines them to "freeze" on these explanations and persist with them even in the face of formidable counterevidence. In the current context, high need-for-closure individuals were hypothesized to prefer simple explanations that portray the past as inevitable, to defend these explanations tenaciously when confronted by dissonant close-call counterfactuals that imply events could have unfolded otherwise, to express confidence in conditional forecasts that extend these explanations into the future, and to defend disconfirmed forecasts from refutation by invoking second-order counterfactuals that imply that the predicted events almost happened. Integrative complexity should be negatively correlated with need for closure. It implies not only a willingness to entertain contradictory ideas but also an interest in generating, testing, and revising integrative cognitions that specify flexible boundary conditions for contradictory hypotheses. The two constructs-need for closure and integrative complexity-are, however, measured in very different ways: a traditional selfreport personality scale in the case of need for closure and an open-ended thought-sampling procedure requiring content analysis in the case of integrative complexity. Given the severe problems of method variance that have bedeviled cognitivestyle research over the past 50 years (Streufert, 1997), a major advantage of the present study is the inclusion of methodologically dissimilar but conceptually overlapping procedures for assessing cognitive style.

The current studies explore individual differences in cognitive style as moderators of how experts respond to close-call counterfactual scenarios that stress the ease with which history could have been redirected down alternative paths. Such scenarios arise frequently in discussions of world politics (Fearon, 1991; Ferguson, 1997; Tetlock \& Belkin, 1996). It is not unusual in both the academic and policy literatures to come across claims of the following sort: "If Archduke Ferdinand had escaped the assassin's bullets in Sarajevo in June 1914, Europe might have been spared World War I," or "If Corporal Hitler had been slain in combat in World War I, Europe might have been spared World War II," or "If President Kennedy had heeded the advice of his hawkish advisors during the Cuban missile crisis, World War III might have been triggered." It is worth emphasizing that one need not take a position on the epistemological merits of close-call counterfactuals to appreciate their psychological significance. Regardless of whether world history is as deeply indeterminate as such arguments suggest, the positions that people take on how close we came to being redirected onto an alternative historical trajectory are likely to be correlated with a host of predispositions, including political ideology, cognitive style, attributions of moral responsibility to particular historical actors, and emotional reactions to particular historical events (cf. Kahneman \& Miller, 1986; Kahneman \& Varey, 1990; Roese \& Olson, 1995, 1996).

The guiding hypothesis is straightforward. Close-call counterfactuals can protect one's belief system from unexpected events that undermine key tenets of one's world view or they can undermine one's belief system by casting doubt on deterministic accounts that portray the past as inevitable. A good example of the belief-system protective function arises when experts predict events that do not transpire but refuse to treat the nonoccurrence as a disconfirmation on the ground that the predicted event almost occurred. Consider the epistemic predicament of Sovietologists who expected in 1988 that the Soviet Communist Party would retain every bit as much authority 5 years hence as it did at the time of the forecast. These experts could and often did argue that the predicted event almost happened: Hardline communists almost restored the party dictatorship in the abortive coup attempt of August 1991.

A good example of how close-call counterfactuals can undermine belief systems arises whenever experts advance confidently deterministic explanations of the past that portray what happened as inevitable but then confront plausible arguments that highlight how easily events might have gone down a different path. For instance, many students of world politics subscribe to some variant of the deterministic thesis that World War I was inevitable - perhaps because of the inherent instability of multiethnic empires (such as Austro-Hungary) and of multipolar balances of power (such as prevailed in pre-1914 Europe) or perhaps because of the widespread perception that the side that mobilized and struck first would possess a decisive advantage in the subsequent struggle. Let us suppose that one challenges these experts with the argument "If the assassination of Archduke Ferdinand on June 28, 1914, had been thwarted, then World War I would not have broken out in August 1914.' These experts have the three following psychologically and logically distinct lines of defense:

1. They could challenge the mutability of the antecedent and insist that it is hard to undo the assassination because the Archduke was so detested in Sarajevo and the Serbian assassins were so determined. Few experts, however, endorse this defense in this case-perhaps because the assassination depends on such an improbable series of coincidences, each of which seems easily "undoable" by the standards of Kahneman and Miller's (1986) norm theory as well as those of Tetlock and Belkin's (1996) minimal-rewrite rule. If security officials had been moderately alert and if the motorcade had not gotten lost in the mazelike streets of Sarajevo (giving a dejected would-be assassin sitting at a sidewalk café a remarkable second chance to do the job right), most experts agree that the assassination would indeed have been thwarted.

2. They could challenge the adequacy of the causal connecting principles linking the antecedent to the hypothesized consequent. Counterfactual arguments are inherently elliptical; it is exhausting to spell out the exhaustive lists of background assumptions that must be satisfied to sustain even the simplest antecedent-consequent linkages. To invoke the standard example, "If the match had been struck, it would have lighted," rests on an elaborate matrix of assumptions, including the presence of oxygen, the absence of water, sufficient friction, and the proper chemical composition of the match. In the case of the Archduke counterfactual, experts could challenge the connecting principles by arguing that Alustro-Hungary was determined to attack Serbia in the summer of 1914 anyway and the assassination had no significant impact on the unfolding of historyit merely provided a convenient casus belli. This defense, incidentally, is also not popular among experts because there is no evidence of any serious preassassination intent to invade.

3. They could concede both the mutability of the antecedent ("Yes, the Archduke could easily have escaped death on July 
$28,1914 ")$ and the soundness of the connecting principles ("Yes, war probably would not have broken out that summer") but then insist that the war would not have been long delayed because some other match would have ignited the conflagration. This defense, which is the most popular of the three, is designated a second-order counterfactual inasmuch as it undoes the undoing of the original close-call counterfactual. Second-order counterfactuals allow for deviations from reality but minimize the significance of the deviations by invoking additional causal forces that soon bring events in the simulated counterfactual world back toward the observed historical path.

If this analysis is correct, individual differences in cognitive style such as need for closure and integrative complexity should be tightly coupled in support of or opposition to close-call counterfactuals. High scorers on need for closure and low scorers on integrative complexity should be especially likely to embrace close-call counterfactuals that protect their conditional forecasts from disconfirmation. These individuals are motivated to believe that the causal understanding of the world that inspired an inaccurate forecast was fundamentally correct. They can preserve this belief by invoking the "I-was-almost-right" defense. By contrast, these same individuals should be especially likely to reject close-call counterfactuals that erode simple deterministic accounts of the past by highlighting how easily events could have been rerouted onto an alternative trajectory. Protecting one's belief system now requires invoking the "I-was-not-a]most-wrong" defense, demonstrating that, although it might initially seem easy to derail a particular historical process, on close inspection it proves remarkably difficult: As soon as one cuts off one causal pathway to the observed outcome, another pathway arises, hydralike, in a second-order counterfactual. In short, the hypothesized epistemic function of close-call counterfactuals should moderate not just the magnitude but also the direction of the correlations between cognitive style and openness to the idea that history is deeply indeterminate. The less flexible and self-critical one's cognitive style, the less accepting one is likely to be of close-call counterfactuals that challenge one's preferred explanations of the past and the more accepting one is likely to be of close-call counterfactuals that protect one's conditional forecasts from refutation.

The first study focuses on backward reasoning in time and on the gadfly function of close-call counterfactuals. Study 1 assesses individual differences among specialists in world politics on the following four dimensions of causal beliefs: (a) the instability of the balance of power as a necessary and sufficient explanation for the outbreak of war in general and for World War $I$ in particular, (b) the efficacy of classic balance-of-power mechanisms in preventing the emergence of hegemons on the European continent in the past few centuries, (c) the Soviet political system as an adequate explanation for both Stalinist tyranny in domestic policy and external expansion in foreign policy, and (d) the role played by nuclear weapons in preventing a third world war between the United States and the Soviet Union. Theoretically, experts who believe that the configuration of international forces in the early 20 th century made the first world war inevitable should be motivated to neutralize closecall counterfactuals that depict the war as easily avoidable. Experts who believe that states are rational actors who coalesce to block would-be world conquerors will try to neutralize close- call counterfactuals that imply that Germany could easily have won either of the two world wars. Also, experts who believe that the Soviet political system was inherently expansionist should resist counterfactuals that imply that the Cold War between the United States and the Soviet Union could easily have been averted. Finally, experts who believe in the efficacy of nuclear deterrence should be particularly dismissive of counterfactuals that imply that the world came perilously close to either a major conventional or nuclear conflict between the United States and Soviet Union. Moreover, these tendencies to dismiss dissonant close-call counterfactuals should be most pronounced among those experts who have a high need for closure and an integratively simple view of the causal dynamics underlying 20 th-century history.

The second study focuses on forward reasoning in time and on the belief-system protective function of close-call counterfactuals. Study 2 examines predictions that experts over the past 10 years have offered for a wide range of political outcomes, including the futures of the Soviet Union, South Africa, and Canada. With benefit of hindsight, it is now possible to classify the 5-year-span predictions as correct or incorrect. The theoretical expectation is that experts who made incorrect predictions should be particularly motivated to defend those predictions by invoking close-call counterfactuals as well as by invoking additional belief-system defenses, such as claiming to be merely off on timing (as one expert indicated in response to an openended measure obtained in Study 2, "the predicted outcome has not happened yet but it soon will") and minimizing the significance of the forecasting failure (as another expert indicated in response to the same open-ended measure, "everyone knows - or else should know - that politics is inherently unpredictable, more cloud-like than clock-like"). Moreover, inaccurate experts with high scores on need for closure and low scores on integrative complexity should rely most on these defenses and therefore should question least the validity of the causal assumptions that inspired the original forecast.

\section{Study 1}

\section{Method}

Participants. Participants were drawn from professional organizations of diplomatic and military historians (e.g., members of the Society for Military History, the Society for Historians of American Foreign Relations, and relevant divisions of the American Historical Association) as well as from professional organizations of international relations specialists and area study specialists (e.g., members of the International Studies Association and relevant divisions of the American Political Science Association and the American Association for the Advancement of Slavic Studies). Response rate was 37\%. Of the 94 participants, 65 had doctorates and the other $29 \mathrm{had}$, on average, 4 years of postgraduate training or relevant work experience. All respondents were guaranteed anonymity and completing the questionnaire required approximately 1 hour.

Causal Beliefs Questionnaire. The Causal Beliefs Questionnaire is a series of instruments that assessed four categories of assertions bearing on the causes of war and peace. All judgments were expressed on 9-point disagree-agree scales, and items were phrased to avoid acquiescence confounds.

Neorealist Balancing Scale. The Neorealist Balancing Scale addressed the importance of balancing as a mechanism for checking would- 
be world conquerors. Items included (a) "For all the talk about a new world order, world politics is still essentially anarchic-the strong do what they will and the weak accept what they must"; (b) "whenever one state starts to become too powerful, other states find a way of combining forces and preventing it from dominating them"; (c) "the security policies of states are often driven by morality, not just by rational calculations of power" (reverse scored); and (d) "it is naive to suppose that the failure of would-be conquerors such as Philip II, Napoleon, and Hitler to achieve lasting dominance in Europe was predetermined by balance-of-power politics-it might just have been an accident" (reverse scored).

Macro Causes of War Scale. The following statements from the Macro Causes of War Scale dealt with beliefs about causal forces often hypothesized to increase the likelihood of war in general and of World War I in particular: (a) "International systems with several great powers are no more likely to erupt into war than are those with only two great powers" (reverse scored); (b) "it is a myth that multiethnic empires are inherently unstable and a threat to world peace" (reverse scored); (c) "changes in the international balance of power-induced by differential growth rates in population and economic power-have historically been the greatest threat to world peace": and (d) "war is most likely when the state of military technology leads decision makers to believe that the side that strikes first will possess a decisive advantage."

Essentialist View of Soviet Union Scale. The following statements from the Essentialist View of Soyiet Union Scale dealt with perceptions of the Soviet Union: (a) "Primary blame for the crimes of the Stalinist period should rest with the Soviet Communist Party, not with any one person"; (b) "after World War II, it was inevitable that the Soviet government would be determined to expand its influence in a fashion that brought it into conflict with the West"; and (c) "the more understanding the U.S. government tried to be of Soviet concerns in the postwar period, the more reasonable the Soviet government became" (reverse scored).

Efficacy of Nuclear Deterrence Scale. The following statements from the Efficacy of Nuclear Deterrence Scale assessed confidence in the stability of nuclear deterrence (see also Tetlock, McGuire, \& Mitchell, 1991): (a) "For all the talk about the risk of nuclear accidents, the United States and the Soviet Union never really came close to nuclear war," (b) "nuclear weapons compelled the American and Soviet governments to act with great restraint during the Cold War," and (c) "it is unrealistic to assume that leaders working under great stress will always act rationally in crises that raise the risk of the use of nuciear weapons" (reverse scored).

Cognitive style measures. The Need for Closure Scale was adapted from a longer scale developed by Kruglanski and Webster (1996) and included the following eight items: "I think that having clear rules and order at work is essential for success"; "Even after I have made up my mind about something, I am always eager to consider a different opinion"; "I dislike questions that can be answered in many different ways"; "I usually make important decisions quickly and confidently"; "When considering most conflict situations, I can usually see how both sides could be right"; "It is annoying to listen to someone who cannot seem to make up his or her mind"; "I prefer interacting with people whose opinions are very different from my own"; and "When trying to solve a problem I often see so many possible options that it is confusing." " Experts rated their agreement with each item on 9-point disagree-agree scales. The Cronbach's alpha for the truncated scale was .77 .

The integrative complexity measure was derived from open-ended responses to a request to reflect on 20th-century history. The following question was used: "Did the 20th century have to be as violent as it has been?" We assured respondents that we understood that many books had been written on this subject and that many more undoubtedly would be written. Our goal was just to get a quick sense for the factors that they deemed most decisive in shaping the general course of events (the sort of shorthand answer they might give a respected colleague in a different discipline at a social occasion). Integrative complexity was coded on a 7-point scale in which scores of 1 were given to statements that identified only causal forces that increased or decreased the likelihood of the specified outcomes (e.g., "Nationalism and mass production of weapons guaranteed disaster"), scores of 3 were assigned to statements that identified causal forces with contradictory effects (e.g., "Twentieth-century history will be remembered not only for the destructive forces unleashed - totalitarianism and weapons of mass destruction-but also for the initial steps toward global governance"), scores of 5 were assigned to statements that tried to integrate two contradictory causal forces (e.g., "Wars can be caused by being too tough or too soft and it is really hard to strike the right balance-that's the big lesson of 20th-century diplomacy"), and scores of 7 placed the problem of integrating causal forces into a broader systemic frame of reference (e.g., "You could argue that we got off lucky and escaped nuclear war or that we were incredibly unlucky and wound up with a holocaust that was the product of one man's obsession. How you look at it is a matter of personal temperament and philosophy. My guess is that we are running about par for the course"). Intercoder agreement was .85 between two raters who were blind to both the hypotheses being tested and to the sources of the material.

Beliefs about close-call counterfactuals. Experts were asked to judge each counterfactual in isolation from the others, always treating the actual historical record as the baseline against which the plausibility of any given what-if scenario must be assessed. The first set of counterfactuals raised the possibility that Germany's failure to achieve hegemony on the European continent in one of the two world wars was by no means foreordained. Close-call counterfactuals that undo the outcome of World War I include the following: (a) "If Germany had proceeded with its invasion of France on August 2, 1914, but had respected the neutrality of Belgium and Luxembourg, Britain would have remained neutral and France would have fallen in a few months"; (b) "If the German high command had implemented the Schlieffen Plan more aggressively in 1914, the miracle of the Marne would have been impossible and Paris would have fallen"; (c) "If France had surrendered in the fall of 1914, Germany would have easily defeated Imperial Russia"; (d) "If Germany had avoided antagonizing the United States through its policies in Mexico and its initiation of unrestricted submarine warfare, the United States would not have entered World War I"'; and (e) "If the United States had not entered World War I in 1917, Germany would have prevailed against the French and British in its spring offensive of 1918."

Counterfactuals that undo the outcome of World War II include (a) "If Goering had continued to concentrate Luftwaffe attacks on British airbases and radar stations, Germany would have won the Battle of Britain"; (b) "If Hitler had opted not to invade the Soviet Union and instead to concentrate German resources against the British, Germany would have defeated Britain"; (c) "If Hitler had more consistently focused the German army on taking Moscow in the summer of 1941, he could have knocked the Soviet Union out of the war"; (d) "If the German military had played more effectively on the widespread resentment of local populations toward the Stalinist regime, the Soviet Union would have collapsed"; and (e) "If Hitler had not declared war on the United States on December 11, 1941, the British and the Soviets by themselves could never have defeated Nazi Germany."

A second set of counterfactuals cast doubt on the inevitability of the first world war: (a) "If the carriage driver of Archduke Ferdinand had not taken a fateful wrong turn that gave the Serbian assassins a remark-

${ }^{1}$ From Motivated Closing of the Mind: "Seizing" and "Freezing," by A. W. Kruglanski and D. M. Webster, 1996, Psychological Review, 103, pp. 263-268. Copyright 1996 by the American Psychological Association. Adapted with permission. 
able second chance to carry out their previously botched assassination plot, war would not have broken out in August 1914"; (b) "If Bethmann-Hollweg had pressured Austro-Hungary more strongly not to declare war on Serbia, war would have been averted"; (c) "If Britain had clearly communicated to Germany its support of France in case of war, Germany would have exercised much more restraint on AustroHungary, thereby defusing the crisis"; and (d) "If Germany had accepted Britain's suggestion in late July of a great power conference to deal with the crisis and had pressured Austro-Hungary to do so too, war would have been averted."

A third set of counterfactuals challenge the inevitability of the Cold War: (a) "If Stalin had died of a cerebral hemorrhage in 1945 rather than in 1953, his successors would have refrained from imposing communist regimes in eastern Europe or giving a green light for the Korean war"; (b) "If Roosevelt had died a year earlier, Henry Wallace, as America's first postwar president, would have done a better job than Truman of reconciling American and Soviet national security concerns"; (c) "If, after the death of Stalin in 1953, the Soviet Union had undergone a process of liberalization comparable with what happened in the mid$1980 \mathrm{~s}$, tensions between the two dominant powers would have eased greatly"; and (d) "If the United States had been more open to Soviet initiatives to defuse tensions in the mid-1950s or in the late Khrushchev period, the Cold War would have thawed much earlier."

A final set of counterfactuals explore ways in which the Cold War might have escalated into a hot (perhaps thermonuclear) war: (a) "If General MacArthur had been allowed to expand the Korean War into the People's Republic of China, World War III would have broken out in the early 1950s"; (b) "If Stalin had lived several years longer ( surviving his stroke but in an increasingly irrational state of mind that encouraged high-risk foreign adventures such as seizing Berlin by force), World War III would have broken out in the mid-1950s"; (c) "If bad weather had delayed the U-2 reconnaissance discovery of Soviet missiles in Cuba until most were already operational, the Soviets would have refused American demands to dismantle and withdraw the weapons"; (d) "If the Soviets had refused to withdraw their missiles in Cuba on the terms that President Kennedy proposed, the United States would have launched air strikes against those missiles"; (e) "If the United States had launched such air strikes, the Soviet commanders in Cuba would have launched at least some missiles at the coast of the United States, triggering a nuclear war"; and (f) "If Soviet hardliners had taken charge of the Communist Party in the mid-1980s, the Cold War would have intensified, eventually leading to a major confrontation over American plans to break out of the Antiballistic Missile Treaty by installing a space-based system for destroying Soviet missiles."

Dependent variables. For each counterfactual, experts responded to three structured queries that correspond to the three lines of possible belief system defense: (a) "How realistic is the starting point or antecedent condition of the argument? (Do we have to 'rewrite' a great deal of history to suppose the antecedent could have become true or do we need to alter only one or two minor coincidences?)"; (b) "Assuming, for sake of argument, that the antecedent condition were true, how likely do you believe it is that the hypothesized consequence would have occurred (from 'virtual impossibility' to 'virtual certainty,' with a midpoint of 50/50 chance)?"; and (c) "Assuming, for sake of argument, that the hypothesized consequence actually did occur, would the effects on subsequent developments have been profound (leading to a radically different world) or insignificant (insignificant because other historical forces would have brought events back in the long run to an end state similar to the real world)?" Experts expressed each judgment on a 9-point disagree-agree scale (with 5 always anchored as maximum uncertainty).

\section{Results}

Constructing a multimethod measure of cognitive style. Observers who scored high on the self-report measure of need for closure tended to score low on the open-ended content analytic measure of integrative complexity, $r=-.41, p<.01$. To simplify exposition of the data, we created a composite cognitive closure and simplicity index by reflecting the scoring of integrative complexity (so that high scores indicated simplicity) and then summing standardized scores on these two variablesa decision that was justified not just by the substantial correlation between the two variables but also by the similar functional relations between each of the two variables and the hypothesized belief-system defense tactics. ${ }^{2}$

Constructing measures of causal beliefs. Each of the four belief-system scales displayed respectable, if less than overwhelming, internal consistency, with Cronbach's alphas ranging from .72 (for endorsing macro causes of war) to 78 (for endorsing an essentialist view of the Soviet political system) to .83 (for both the neorealism and nuclear deterrence scales). As expected, there were also positive intercorrelations among scales, with high scores on the Neorealist Balancing Scale covarying with endorsing the Efficacy of Nuclear Deterrence Scale $(r=.58)$, the Essentialist View of the Soviet Union Scale $(r$ $=.48)$, and the Macro Causes of War Scale $(r=.35)$. The correlations between the Causal-Beliefs Scales and the multimethod composite measure of cognitive closure and simplicity ranged between .12 and .24 .

Constructing measures of belief-system defense. The three strategies of neutralizing close-call counterfactuals - denying the close-call status of the antecedent, impugning the validity of the causal connecting principles linking antecedent to consequent, and invoking second-order counterfactuals that concede that history could have been sidetracked but only brieflyturned out to be substantially intercorrelated across most of the close-call counterfactuals presented to experts (average $r=$ .39). To enhance the reliability of our dependent measure of belief-system defense and to simplify presentation, therefore, we summed the three scales assessing endorsement of the three strategies and created a composite index to capture the overall intensity of resistance to any given close-call counterfactual.

We also explored the feasibility of creating an even more reliable scale by aggregating not only across strategies of fending off close-call counterfactuals but also across close calls that altered the same historical outcome. Reactions to counterfactuals that "undid" the first world war had an average correlation of .31; reactions to counterfactuals undoing the outcomes of the first and second world wars had average correlations of .36 and .40; reactions to counterfactuals undoing the Cold War had an average correlation of .44; and reactions to counterfactuals un-

\footnotetext{
${ }^{2}$ Notwithstanding the substantial correlation between the two measures, skeptics might question the appropriateness of combining a domain-general measure of cognitive style such as need for closure with a domain-specific measure of the integrative complexity of experts' assessments of 20th-century history. The latter measure is much closer conceptually to the dependent variable than is the former measure and may thus "artificially" inflate predictive links between cognitive style and resistance to close-call counterfactuals. Although the two cognitivestyle measures jointly explain more variance than either measure separately in Study I, the domain-general closure scale slightly but consistently outperforms the domain-specific measure of integrative complexity in the relevant multiple regressions.
} 
doing the outcome of the Cold War had an average correlation of .38. This clustering of judgments justified a further aggregation of data into five dependent variables corresponding to the five key historical events targeted for undoing by the counterfactuals.

Testing core hypotheses. High need-for-closure and simplicity experts should most resist close-call counterfactuals that challenged an existing network of beliefs about historical causality. To test this idea, a series of multiple regressions simultaneously assessed the predictive power of the Causal Beliefs Scale, the composite measure of cognitive style, and the Cognitive Style $\times$ Causal Belief interaction for each set of closecall counterfactuals, thus permitting five separate tests of the hypothesis. All independent and dependent variables were centered about the means of their respective distributions to standardize metrics and to facilitate interpretation of potential interactions. Table 1 summarizes these regressions, each of which explained between $34 \%$ and $48 \%$ of the variance in reactions to close-call counterfactuals.

Each Causal Beliefs Scale performed as hypothesized. Experts who subscribed to the neorealist balancing schema were more likely to reject close-call counterfactuals that implied that Germany could easily have emerged victorious in either of the two world wars. Experts who believed in nuclear deterrence were especially dismissive of close-call counterfactuals in which the United States and the Soviet Union could easily have slipped into nuclear war at various junctures in the Cold War. Experts who adhered to a more essentialist view of the Soviet Union displayed little patience with close-call counterfactuals that implied that the Cold War might have been avoidable by changing the leaders of either superpower. Experts who endorsed macro causes for war in general and of World War I in particular were more skeptical of counterfactuals that allowed the world to escape the cataclysm of 1914 .

Table 1

Multiple Regression Analyses for Predicting Resistance to Close-Call Counterfactuals at Key Junctures in 20th-Century History

\begin{tabular}{lcccc}
\hline Historical juncture and variable & $S E$ & $\beta$ & $t$ & $p$ \\
\hline Undoing WWI & & & & \\
$\quad$ Cognitive style & 2.46 & .12 & 0.78 & $n s$ \\
$\quad$ Macro causes of war & 0.21 & .80 & 9.38 & .01 \\
$\quad$ Interaction & 0.12 & .40 & 2.62 & .01 \\
Undoing outcome of World War I & & & & \\
$\quad$ Cognitive style & 1.95 & .32 & 2.05 & .04 \\
$\quad$ Neorealist balancing & 0.17 & .86 & 8.76 & .01 \\
$\quad$ Interaction & 0.09 & .57 & 2.75 & .01 \\
Undoing outcome of World War II & & & & \\
$\quad$ Cognitive style & 2.28 & .28 & 1.37 & $n s$ \\
$\quad$ Neorealist balancing & 0.20 & .73 & 10.69 & .00 \\
$\quad$ Interaction & 0.10 & .35 & 1.73 & $n s$ \\
Undoing Cold War & & & & \\
$\quad$ Cognitive style & 2.48 & .35 & 1.49 & $n s$ \\
$\quad$ Essentialist view of Soviet Union & 0.26 & .74 & 7.21 & .01 \\
$\quad$ Interaction & 0.14 & .21 & 0.88 & $n s$ \\
Undoing Cold War outcome &. & & & \\
$\quad$ Cognitive style & 2.53 & .42 & 1.93 & $n s$ \\
$\quad$ Efficacy of nuclear deterrence & 0.25 & .80 & 9.45 & .01 \\
$\quad$ Interaction & 0.13 & .67 & 3.10 & .01 \\
\hline
\end{tabular}

The multiple regressions revealed only one significant main effect for the cognitive-style variable of need for closure and simplicity (low scorers on the scale were more open to the possibility that the Cold War could have ended in a thermonuclear apocalypse) and a succession of four nonsignificant effects in the same direction (lower scorers were more open to rerouting history). This result offers at best equivocal support to the trait hypothesis that flexible, multidimensional thinkers are more open to the idea that history could have unfolded in radically different ways.

The predicted interactions between cognitive style and the belief-system variables did, however, emerge with more impressive consistency, achieving significance in three of the five regressions and approaching it in a fourth. As Table 1 reveals, high scorers on both the Macro Causes of War Scale and closure and simplicity were especially dismissive of close-call counterfactuals that imply World War I could have been avoided; high scorers on the Neorealist Balancing Scale and closure and simplicity were especially resistant to close-call counterfactuals that implied that Germany could have won either World War I or II; and high scorers on both the Efficacy of Nuclear Deterrence Scale and closure and simplicity were especially skeptical of close-call counterfactuals that implied the Cold War might have ended far less peacefully than it did. The major exception concerned reactions to counterfactuals that undid the Cold War. The interaction between cognitive style and the relevant beliefsystem variable-a view of the Soviet Union as inherently expansionist - did not even approach significance.

To simplify the patterns in the data even more dramatically, principal-component analysis was performed to assess the correlational structure of both the independent and dependent variable scales. As Table 2 reveals, all four of the belief-system scalesendorsing macrocauses of war, balance-of-power politics as a means of blocking would-be hegemons, an essentialist view of the Soviet Union, and a faith in nuclear deterrence-loaded positively (above .40 ) on the first component which we have accordingly labeled the Anticommunist Realpolitik Scale. In a separate principal-components analysis, resistance to the five sets of close-call counterfactuals also loaded positively on a common component (loadings above .35 ) which we have labeled accordingly the Deterministic View of Twentieth-Century History Scale. We then computed scores for individual experts on each of these two components and performed a multiple regression that included the Anticommunist Realpolitik Scale, cognitive-style scores on simplicity and closure, and the interaction term as independent variables and the Deterministic View of 20th-Century History scale as the dependent variable. As Table 3 indicates, the results largely reinforce the earlier conclusions. The regression accounts for $49 \%$ of the variance in judgments of close-call counterfactuals. The Anticommunist Realpolitik Scale emerges as the dominant predictor of endorsing a deterministic view of 20th-century history, and this scale is an especially potent predictor among experts with high needs for closure and simplicity. As the three-dimensional plot in Figure 1 reveals, resistance to close-call counterfactuals - to the notion that history could have unfolded very differently - peaks in the area of the regression plane corresponding to high scores on both the Anticommunist Realpolitik Scale and Need-for-Closure and Simplicity measure. 
Table 2

Variable Loadings on First Principal Components Derived From Causal Beliefs Scales and From Resistance to Close-Call Counterfactuals

\begin{tabular}{|c|c|c|c|}
\hline Causal-Belief Scale & $\begin{array}{l}\text { Anticommunism } \\
\text { realpolitik } \\
\text { component }\end{array}$ & Close-call counterfactual scale & $\begin{array}{l}\text { Deterministic view } \\
\text { of } 20 \text { th-century } \\
\text { history component }\end{array}$ \\
\hline Neorealist Balancing & .85 & Undoing outcome of Cold War & .75 \\
\hline Efficacy of Nuclear & & Undoing Cold War & .63 \\
\hline Deterrence & .80 & Undoing World War I & .64 \\
\hline Essentialist View of the & & Undoing outcome of World War I & .83 \\
\hline Soviet Union & .73 & Undoing outcome of World War II & .80 \\
\hline Macro Causes of War & .65 & & \\
\hline
\end{tabular}

But the principal-component analysis also rescues a hypothesis that we might have rejected if we had relied simply on significance testing derived from the five separate multiple regressions. The closure and simplicity measure which failed the latter test now emerges as an independent predictor. The higher one's scores on closure and simplicity, the more closed one is likely to be to close-call counterfactuals that depict history as profoundly indeterminate. A trend that was in the expected direction but too weak to achieve significance in four of the five regressions involving individual causal-beliefs and counterfactual scales became much easier to observe once the CausalBeliefs Scales had been combined into a composite Anticommunist Realpolitik Scale and the counterfactual scales had been combined into a composite determinism scale - almost a textbook demonstration of the capacity of data reduction techniques to enhance statistical power by reducing the "noisiness" of both independent and dependent variables.

\section{Discussion}

The impressive power of the belief-system variables to predict resistance to close-call counterfactuals is not, by itself, all that astonishing. Indeed, skeptics might invoke a Kantian distinction and argue that the relationship between the two classes of constructs is analytic, rather than synthetic, a logical rather than a causal connection (admittedly a blurry distinction in modeling belief systems). Consider, for example, experts with an essentialist outlook on the Soviet Union who believe that Stalin was no aberration, just the logical continuation of the Leninist legacy, and that, given its domestic political system, the Soviet Union had to have an expansionist foreign policy after World War II. Are not these experts pretty much obliged to argue against

Table 3

Multiple Regression Analysis Using Specific Variables to Predict Deterministic Outlook on the 20th Century (Aggregated Resistance to Close-Call Counterfactuals)

\begin{tabular}{lcccc}
\hline \multicolumn{1}{c}{ Variable } & $b$ & SE $b$ & \multicolumn{1}{c}{$t$} & $p$ \\
\hline Anticommunist Realpolitik Scale & .90 & .04 & 20.41 & .001 \\
Cognitive Scale & .14 & .03 & 5.16 & .011 \\
Interaction & .06 & .02 & 2.64 & .01 \\
\hline
\end{tabular}

counterfactual claims that the Cold War could easily have been avoided by moving the occurrence of Stalin's cerebral hemorrhage up by 7 or 8 years or by advancing President Roosevelt's stroke by 1 year, thereby replacing Truman with a relatively left-wing president (Wallace)? Similarly, are not experts who believe in the inherent stability of nuclear deterrence and the rationality of policy makers obliged to be skeptical of counterfactuals that insist that the world came precariously close to a nuclear Armageddon? It would be odd if experts who have devoted many years of study to world politics did not readily make these conceptual connections, producing hefty prediction coefficients in the process.

Be that as it may, the surprising result was the robust moderator-variable role played by the multimethod composite measure of cognitive style. Some experts' belief systems are apparently much more tightly integrated than those of others. And these experts have consistently higher scores on the measure of clo-

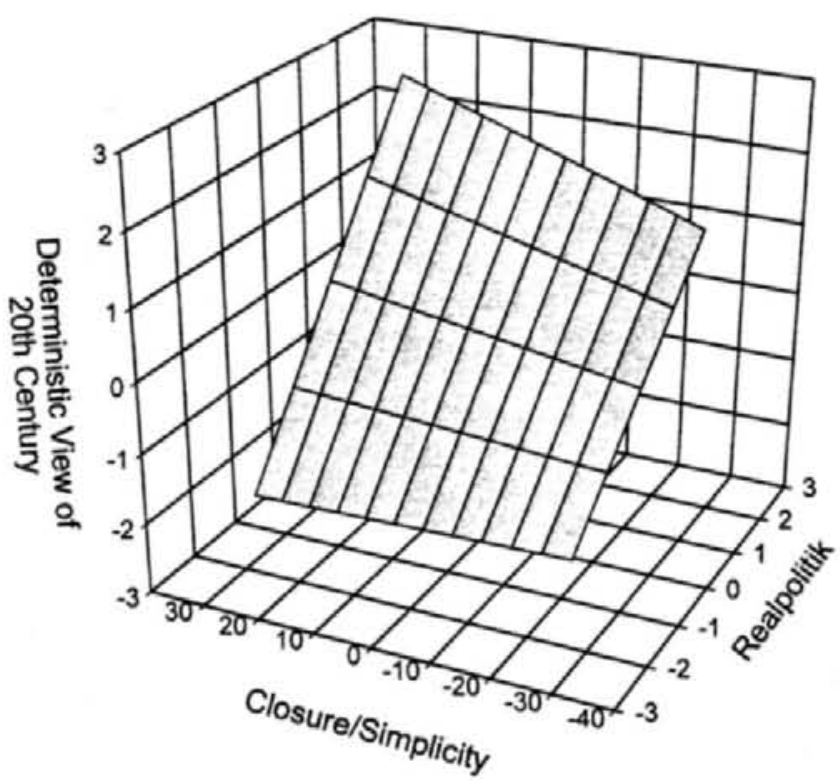

Figure 1. Predicting overall resistance to close-call counterfactuals that undo key aspects of 20th-century history as a function of the Composite Anticommunist Realpolitik Scale and need for closure and simplicity. 
sure and simplicity. Here one is confronted with an interesting interpretive choice. Academic observers can either (a) applaud the high closure and simplicity respondents for their logical rigor and taut belief systems and deplore their low closure and simplicity counterparts for their mental sloppiness and looselinkage belief systems; or (b) criticize the high closure and simplicity respondents for their mental rigidity and lack of historical imagination and praise their low closure and simplicity counterparts for their cognitive flexibility and vision. These diverging evaluations can be readily fit into a 2 (positive-negative) $\times 2$ (low-high on descriptive dimension) Peabody (1967) plot of the sort that Tetlock, Armor, and Peterson (1994) constructed for integrative simplicity-complexity (see also Tetlock, 1992a, 1994; Tetlock et al., 1994). These diverging evaluations also tie directly into old debates between cognitive consistency theorists over how loosely or tightly integrated belief systems tend to be, with minimalists such as Abelson (1968) stressing the lack of connectedness among idea elements and maximalists such as McGuire (1968) seeing more potential for constraint. The current findings suggest that experts' political belief systems are indeed fairly tightly constrained and that the degree of constraint is a function of cognitive style.

It is also worth commenting on the success in (a) creating a composite measure of cognitive style that possesses considerable convergent validity and (b) demonstrating the predictive power of this measure in a novel setting. Cognitive styles have long eluded multimethod triangulation (Vannoy, 1965), and it is instructive to ask why this effort succeeded whereas others (including some of our own efforts) have failed. In a nutshell, the current study created almost ideal conditions for observing powerful cognitive-style effects. First, respondents were unusually sophisticated and possessed extensive knowledge of most of the issues on which we elicited judgments. They were familiar with both the theoretical debates alluded to in the Causal Beliefs Scales and with the historical controversies alluded to in the close-call counterfactual scales. There was thus minimal variation in ability or knowledge to obscure the cognitive-style effects. Second, counterfactual history places, by definition, few reality constraints on judges who are thus free to accept or reject scenarios consistent with their political outlook and cognitive style. The analogy is imperfect, but counterfactual interpretation is akin to responding to a semiprojective test (a traditional method of assessing cognitive styles which were once thought to be best elicited by sentence stems that primed uncertainty and conflict-Loevinger, 1976; Suedfeld, 1983). Third, the counterfactual scenarios were emotionally and cognitively engaging for most respondents - the sorts of scenarios likely to elicit "dominant" or ideologically well-rehearsed responses according to classical motivational theories. In some cases, respondents had staked their public reputations on the validity of either particular theoretical generalizations or close-call counterfactual exceptions.

Overall, the data underscore the usefulness of positing a belief-system continuum that is anchored at one end by low closure and simplicity theorists of world politics who accept that there are many possible ways in which 20 th-century history could have worked itself out and anchored at the other end of the continuum by high closure and simplicity theorists who insist that things pretty much had to work out as they did and have little tolerance for "counterfactual fantasies." Toward the middle of the continuum is the bulk of our sample: theorists who acknowledge systemic constraints on what could have happened but who concede that it was often possible for history to stray, sometimes for prolonged periods, from the observed path. These latter theorists give their counterfactual imaginations far freer rein than their high closure and simplicity counterparts but are much more likely to rein in their counterfactual imaginations than their low closure and simplicity counterparts.

The implications for current theories of counterfactual reasoning also merit note. Following Kahneman and Miller (1986), the existing literature has depicted counterfactual reasoning as largely data driven. In this view, people pay disproportionate attention to surprising events that deviate from "perceptual norms" and they devote considerable effort to explaining such events and generating counterfactuals that undo these deviations, thereby returning history to normality. By contrast, the current study is almost custom designed to demonstrate theory-driven properties of counterfactual reasoning. The experts had elaborate and explicit networks of political schemata for filling in the missing control conditions of history. Moreover, the experts had little reason to fear falsification (no one, after all, can travel to these "possible worlds" to assess definitively what would have happened). The resulting theory-driven character of expert thought was reflected in (a) the substantial intercorrelations among the three strategies of resisting close-call counterfactuals (average $r=.39$ ) and (b) the hefty correlations between each causal belief scale and the relevant resistance strategies.

One should be careful, however, not to exaggerate the topdown, deductive character of the reasoning observed. The counterfactual reasoning of experts is best characterized as a subtle blend of theory and data-driven components (cf. Roese, 1997; Johnson \& Sherman, 1990). Two strategies of resisting closecall counterfactuals-challenging connecting principles and generating second-order counterfactuals - appear to be largely theory driven. The two strategies are highly correlated with each other $(r=.59)$ as well as with abstract theoretical and ideological orientations toward world politics (average correlation of .54 with the Causal Beliefs Scales). But the third strategychallenging the mutability of historical antecedents - was more weakly correlated with the other two strategies ( $r=.30$ and .31$)$ as well as with abstract theoretical and ideological orientations toward world politics (average $r=.29$ ). These results make good sense within the context of Kahneman and Miller's (1986) norm theory. Judgments of the mutability of historical antecedents should be highly context bound and not tightly coupled to abstract orientations toward world politics. There is no compelling reason, for example, why one's theoretical position on macro causes of war should predict whether one believes the assassination of the Archduke on June 28, 1914 in Sarajevo could easily have been thwarted or why one's position on the robustness of nuclear deterrence should predict whether one believes Stalin could have survived his cerebral hemorrhage of March 1953 or whether Cuba could have been cloudier on key days in October 1962. The plausibility of these antecedents hinges on specific facts tied to particular times, places, people, and events; if anything, it is surprising-some might argue, disturbing - that abstract theoretical orientations predicted as much of the variance ( $8 \%$ to $12 \%$ of the variance) as they did in 
judgments of the mutability of antecedents. It is not surprising, however, that abstract theoretical orientations emerged as potent predictors of the short- and long-term consequences that experts believe flow from altering particular historical antecedents. The psychologic linking antecedents to consequences must derive, in substantial measure, from abstract beliefs about cause-effect relationships in world politics.

In closing the discussion of Study 1 , it is worth reiterating that the functional interrelationships among cognitive style, openness to close-call counterfactuals, and belief-system defense will not always take the form observed here. The analytic spotlight has thus far been on how experts react to close-call counterfactuals that poke indeterminacy holes in causal schemata that experts rely on to varying degrees to render the past intelligible. When one shifts the focus from explaining the relatively distant past to predicting the relatively near-term future, experts' belief systems become vulnerable to a new and arguably more difficult-to-dismiss threat-namely, disconfirmation. Rather than being an epistemic nuisance, close-call counterfactuals now emerge as a potentially useful weapon of belief-system defense: the "I-was-not-almost-wrong" defense.

\section{Study 2}

Over the past 12 years, I (Tetlock, 1992b, 1998) have been collecting experts' predictions of a wide array of political, economic, and military outcomes. The goal has been not only to document correlates of judgmental accuracy but also to explore how experts react to the apparent confirmation or disconfirmation of their expectations over the course of several years. This. article focuses on a subset of these predictions - those that have come due, that lend themselves to clear classification as right or wrong, and that have been the subject of follow-up interviews in which experts were asked to reflect on what happened in the intervening 5- to 10-year period and on the implications of those events for their own world view. These predictions fall into three domains: the future governance of the Soviet Union as seen by experts in 1988, the future of South Africa as seen by experts in 1989, and the future of Canada as seen by experts in 1992.

The key hypothesis was that low closure and simplicity experts would be especially likely to concede that conditional forecasts of events that do not materialize have indeed been disconfirmed. They would, in brief, be more open to the possibility that they erred-either that their factual assessment of antecedent conditions was wrong or that their assumptions about political causality were awry. By contrast, high closure and simplicity experts should resist the modus tollens syllogism: If $\mathrm{X}$, then $\mathrm{Y} ; \mathrm{X}$ indisputably occurs and $\mathrm{Y}$ does not; therefore, something is wrong with the causal connecting principles that were the basis for the original prediction. Specifically, these experts were expected to avail themselves of the following four distinct lines of defense for insulating conditional forecasts from refutation. 1. Claim that although the specified antecedent was satisfied, key background conditions covered by the ceteris paribus clause took on unexpected values, thereby short-circuiting the otherwise reliably deterministic connection between cause and effect. For example, experts might insist that rapid privatization of state industries would have led to the predicted surge of economic growth but only if the government had exercised pru- dent control over the money supply. 2. Invoke close-call counterfactuals that maintain that, although the predicted outcome did not occur, it almost occurred and would have but for some inherently unpredictable exogenous shock. Examples include "The hardliners almost succeeded in their coup attempt against Gorbachev"; "The Québecois separatists almost won the secessionist referendum that would have torn apart Canada"; and "But for the coincidence of de Klerk and Mandela, there would have been a lot bloodier transition to black majority rule in South Africa." 3. Invoke the off-on-timing defense which maintains that, although the predicted outcome has not yet occurred, it eventually will and we just need to be more patient. Communism may yet return to Russia, Canada may still dissolve, and savage interracial and tribal warfare may still erupt in South Africa. 4. Trivialize failure by arguing that, although the relevant preconditions were satisfied and the predicted outcome never came close to occurring and now never will, we should not hold this failure against the framework that inspired the original forecast. Politics is inherently unpredictable, more cloudlike than clocklike, and forecasting exercises are best viewed as light-hearted diversions of no great consequence.

A critical consequence of the differential responses of low versus high scorers on closure and simplicity merits noting. Low scorers who make inaccurate conditional forecasts should lose confidence in both their understanding of underlying causal forces and of the antecedent conditions on which those causal forces operated. They should therefore be relatively open to the possibility that they did not appreciate what was happening on the ground (e.g., "If I had known the Soviet economy was in that bad shape, I'd have been more pessimistic about the Communist Party's hold on power") or that the conceptual schema they used to draw inferences from the data was flawed (e.g., "I thought the weakening economy would have strengthened the hand of the disciplinarians, not the democrats"'). By contrast, high closure and simplicity experts who make inaccurate conditional forecasts should lose little confidence in their grasp of the prior situation or of the causal forces at work. Their belief systems have been buffered by a four-tier protective belt of defensive tactics. As a result, these respondents should express every bit as much confidence in their overall world view as those respondents whose conditional forecasts were actually borne out by subsequent events.

\section{Method}

Participants. Respondents were all highly educated professionals who had received some graduate training in social science and history (at least to the master's-degree level) and who earned their livelihoods by analyzing trends in the identified regions or nation-states either as advanced graduate students and professors in universities, policy analysts in think tanks or international agencies such as the World Bank and International Monetary Fund, intelligence analysts in government service, or journalists employed by the mass media. The sample sizes for experts who made predictions in their domains of expertise and who were successfully recontacted were as follows: 5-year predictions for the future of Soviet communism in $1988(n=38)$, 5-year predictions for the future of White minority rule in South Africa in $1989(n=26)$, and 5-year predictions for the future of Canadian confederation in 1992 ( $n=29$ ). However, the total number of predictions for each target event was substantially larger than the number of area specialists because out- 
of-area specialists were encouraged to venture forecasts outside their formal domains of expertise. Sample sizes for these predictions range between 79 and 83 .

Procedure. The task instructions stressed that although political forecasting is obviously an inexact science, educated guesswork is critical for setting priorities and making contingency plans. The instructions also assured experts that all predictions they advanced would be completely confidential and not be traceable to them personally (an assurance that proved especially reassuring to those in corporate or government service). The goal was not to proclaim "winners" and "losers" in a forecasting contest but rather to study how experts reason about complex events under conditions of uncertainty. We then posed variants of the following question:

Consider the basic forces - be they international, domestic political, economic, cultural, or psychological-that in your judgment are currently shaping events in $[x]$. Assuming that those same underlying forces continue to be influential [in the specified time period], what kind of future do you see for $[\mathrm{x}]$ ?

Respondents then selected from a menu of scenarios. In the Soviet case, these scenarios included a strengthening, a reduction, or no change in Communist Party control. In the South African case, the scenarios included movement toward more repressive White minority control, continuation of the status quo, less repressive White minority rule but no serious power sharing with Blacks, and major movement toward formal establishment of Black majority rule. In the Canadian case, the scenarios included the formal secession of Quebec, continuation of the constitutional status quo, or a major effort to work out an intermediate "special-status" solution within confederation.

Respondents also rated their confidence in their forecasts on subjective probability scales ranging from 0 (confident it is false) to 1.0 (confident it is true) and were given detailed instructions on how to quantify their uncertainty. Subjective probabilities assigned to scenarios were supposed to sum to 1.0 (participants who felt the options were not mutually exclusive or exhaustive were given an opportunity to respecify outcomes or to insert write-in candidates, but only a few did so), and the subjective probabilities assigned to the option chosen as most likely were always supposed to be at least equal to, or greater than, the subjective probability labeled "maximum uncertainty" (which in two-scenario cases was .5, in three, .33, and so forth). Respondents were told that it was acceptable to assign guessing confidence to all scenarios and, indeed, were asked to do exactly that if they felt that they truly had no basis for rating one scenario as more probable than the others. However, when participants assigned less than guessing confidence to the scenario chosen as most likely, they were asked to reconsider whether they still wished to select that scenario or to switch to one they now deemed more likely.

After the specified interval for predictions had elapsed, efforts were made to recontact as many participants as possible (roughly $78 \%$ were both contacted and agreed to be questioned again). After exploring experts' ability to recall their original answers, experts were reminded of the options they were given, their original forecasts, and their confidence estimates. Experts rated on 9-point agree-disagree scales the degree to which they believed that (a) the antecedent condition for their forecast had been fairly satisfied (the assumption that the same underlying forces would continue to be influential), (b) alterations in previously unspecified background conditions (things too numerous to mention but all potentially important) could easily have altered the predicted outcome, (c) alternative outcomes almost occurred (specify alternative outcomes), (d) alternative outcomes still might yet occur (specify alternative outcomes), (e) forecasting exercises have the potential to yield important insights into the validity of competing political points of view, (f) forecasting exercises should not be taken seriously because politics is inherently unpredictable, $(\mathrm{g})$ forecasting exercises should not be taken seriously because the outcomes may be predictable but are under the control of causal forces that are either unknowable or known only to a small circle of key decision makers, and (h) forecasting exercises are deeply misleading because they assign too much credit to the "lucky winners" and too much blame to the "unlucky losers."

Experts were also asked to recall the subjective probability they assigned to their earlier forecasts and to assign a subjective probability estimate to the confidence they now possessed in their understanding of what happened in the target country. Finally, all experts judged which of the "possible futures" identified earlier came closest to capturing what actually happened in the specified period. There was over $90 \%$ agreement on the "right answer" in these three cases (collapse of communism, continuation of Canadian constitutional status quo, and transition to multiracial democracy). This expert-consensus judgment defined the accuracy criterion for this study.

Cognitive-style assessments. Integrative complexity was assessed at the time of the original forecasts (1988 or 1992) by scoring open-ended responses to questions such as "Why do you view [insert outcome assigned greatest subjective probability] as most likely?"' The same construct was also assessed when the specified 5-year forecasting interval had elapsed: "In your opinion why did what happened occur?" The same abbreviated version of the Need for Closure Scale used in Study 1 was assessed as part of a "work-style" questionnaire included in a (recontact) mail and telephone survey in 1997 of participants in earlier rounds of the forecasting studies.

\section{Results}

Cognitive style. Integrative complexity had moderate within-domain stability over the 5-year forecasting period. Participants who offered complex justifications for their original predictions displayed similar styles of reasoning in their explanatory postmortems for the Soviet Union $(r=.42)$, South Africa $(r=.38)$, and Canada $(r=.32)$. The trait measure of integrative complexity (combined score over time) was again correlated with the need-for-closure measure, albeit more weakly than before $(r=.31)$.

Forecasting accuracy and confidence calibration. Across all three scenarios, experts and nonexperts alike were only slightly more accurate than one would expect from chance. Almost as many respondents as not thought that the Soviet Communist Party would remain firmly in the saddle of power in 1993, that Canada was doomed by 1997 , and that neofascism would prevail in Pretoria by 1994.

Although experts only occasionally exceeded chance predictive accuracy, they regularly assigned subjective probabilities that, on average, exceeded the scaling anchors for "just guessing." In this sense, the results replicate the already well-established overconfidence effect (Fischhoff, 1982). Most experts thought they knew more than they did. Moreover, the margins of error were larger than customarily observed in research on the calibration of confidence. Across all three predictions, experts who assigned confidence estimates of $80 \%$ or higher were not correct more than $40 \%$ of the time. By contrast, nonexperts who ventured opinions on regions outside their field of study were markedly more modest, across domains average confidence of experts versus nonexperts, $M \mathrm{~s}=68 \%$ and $54 \%, t(153)=$ $2.54, p<.05$, and hence less prone to overconfidence.

Cognitive reactions to the confirmation and disconfirmation of forecasts. Our principal interest here was, however, in neither forecasting accuracy nor confidence calibration nor in comparisons of experts and nonexperts, but rather in experts' reac- 
tions to the apparent confirmation or disconfirmation of their forecasts. Not surprisingly, experts who got it right credited their accuracy to their sound reading of the "basic forces" at play in the situation. Across issue domains they assigned average ratings between 6.5 and 7.6 on a 9-point scale where 9 indicates maximum confidence. Perhaps more surprisingly, experts who got it wrong were almost as likely to believe that their reading of the political situation was fundamentally sound. They assigned average ratings from 6.3 to 7.1 , across domain $t(56)=0.98$, $n s$.

How did experts who got it wrong convince themselves that they were basically right? Table 4 reveals considerable support for the core hypothesis that these forecasters preserved confidence in their world view by invoking various combinations of belief-system defenses. One popular defense was to advance close-call counterfactuals in which experts assert that the world they predicted "almost occurred." Consider the following two examples:

1. In contrast to observers who foresaw reduced party control and further democratization, Sovietologists who predicted a 5year trend toward greater Communist Party control and renewed authoritarianism in 1988 were much more prone to claim that hardliners almost succeeded (for example, in the coup attempt of August 1991) and might well have succeeded had it not been for their own monumental ineptitude or the courage of political leaders and military officers who resisted the coup, $M \mathrm{~s}=7.0$ versus $4.1 ; t(35)=3.62, p<.001$.

2. Observers of South Africa who expected White minority rule to continue or to become increasingly oppressive from $1988-1989$ to $1993-1994$ were especially likely to believe that were it not for the coincidental conjunction of two key individuals - de Klerk and Mandela-in key leadership roles, South Africa could easily have gone down the path of increasing repression, racial polarization, and violence, $M \mathrm{~s}=7.1$ versus 4.5 ; $t(25)=2.65, p<.01$.

Canada did, however, pose a partial exception. Here, as predicted, experts who anticipated the secession of Quebec from Canada frequently pointed to how nearly the second separatist referendum passed (if a fraction of a percentage point of the electorate had voted "oui" rather than "non") and to how a more effectively managed campaign could have easily won a larger fraction of the swing vote if, say, a more savvy and charismatic politician-Bouchard rather than Parizeau - had spearheaded the cause. But the accurate forecasters were almost as likely in this case to accept close-call counterfactuals, $M \mathrm{~s}=$ 7.6 versus 6.8 , yielding a trend that fell short of significance, $t(26)=1.05, n s$. Apparently, a $50.1 \%$ "non" vote in the referendum looked like a close call to almost everybody.

Table 4 also reveals that experts resort to other belief-system defenses. Relative to accurate forecasters, inaccurate ones were more likely to argue that the ceteris paribus clause had not been satisfied because a qualitatively new array of "fundamental forces" had come into play, across domains, $M \mathrm{~s}=6.9$ versus $3.7, t(90)=2.89, p<.05$. Inaccurate forecasters were also more prone to argue that they had just been "unlucky" on timing, across domains, $M s=6.1$ versus $4.5, t(90)=2.51, p$ $<.05$. This defiant defense was especially popular among those who predicted the demise of Canada (the Parti Québecois will try again and prevail on its third attempt). Finally, there was a pronounced tendency for experts who got it wrong to be more dismissive, even contemptuous, of forecasting exercises than were experts who got it right, across domains, $M s=7.2$ vs. $4.2, t(89)=2.73, p<.05$. This set of dependent variables is of special interest because it is the only strategy for coping with disconfirmation that could be assessed both before experts made their predictions and after they learned of the accuracy of their predictions. Inaccurate forecasters became much more likely to agree with the sentiments that (a) politics in general is inherently indeterminate and (b) the specific outcomes being predicted were largely under the control of causal forces that were either unknowable with the requisite precision or knowable only to a small group of key decision makers, matched pairs $t(55)=$ $2.39, p<.05$. By contrast, there was a nonsignificant trend in the opposite direction among accurate forecasters who became more favorably inclined toward forecasting exercises as vehicles for exploring the relative validity of competing political points of view, matched pairs $t(44)=1.36, n s$.

Cognitive closure and simplicity was also related to endorsement of belief-system defense tactics. The relationship was significant, however, only among inaccurate forecasters for whom higher scores on closure and simplicity translated into stronger endorsements of close-call counterfactuals ( $r=.35$ ), the offon-timing defense $(r=.27)$, and minimizing the significance of forecasting accuracy $(r=.29)$, collapsing across all three forecasting domains. No such relationship emerged among accurate forecasters (all $r$ s hovering between -.10 and .10 ).

Turning to the impact of political outcomes on ex post confidence, there was, as noted earlier, surprisingly little difference in the confidence that accurate and inaccurate forecasters expressed in the correctness of their understanding of underlying forces, overall, $M s=6.8$ versus 6.5 , respectively. Cognitive style does, however, emerge again as a differential predictor - an

Table 4

Mean Reactions to Confirmation and Disconfirmation of Conditional Forecasts (Including Only Specialists)

\begin{tabular}{|c|c|c|c|c|c|c|}
\hline Issue domain & $\begin{array}{l}\text { Belief-system defenses: } \\
\text { Status of forecast }\end{array}$ & $n$ & $\begin{array}{l}\text { Close-call } \\
\text { counterfactuals }\end{array}$ & $\begin{array}{l}\text { Ceteris paribus } \\
\text { did not hold }\end{array}$ & $\begin{array}{l}\text { Just unlucky } \\
\text { about timing }\end{array}$ & $\begin{array}{l}\text { Dismiss forecasting } \\
\text { exercises in general }\end{array}$ \\
\hline \multirow[t]{2}{*}{ Soviet Union } & Inaccurate & 27 & 7.0 & 7.1 & 6.4 & 7.3 \\
\hline & Accurate & 11 & 4.1 & 3.9 & 5.0 & 3.1 \\
\hline \multirow[t]{2}{*}{ South Africa } & Inaccurate & 15 & 7.1 & 7.0 & 3.7 & 7.1 \\
\hline & Accurate & 11 & 4.5 & 3.5 & 4.0 & 4.8 \\
\hline \multirow[t]{2}{*}{ Canada } & Inaccurate & 15 & 7.6 & 6.8 & 8.0 & 7.2 \\
\hline & Accurate & 14 & 6.8 & 3.7 & 4.4 & 4.5 \\
\hline
\end{tabular}


insignificant predictor of ex post confidence among accurate forecasters $(r=.09)$ and a much more powerful predictor among inaccurate forecasters $(r=.39)$. Moreover, the relationship between cognitive style and ex post confidence among inaccurate forecasters falls to nonsignificance as soon as one controls for endorsement of close-call counterfactuals (partial $r=$ .11 ) or the off-on-timing defense (partial $r=.14$ ), suggestive evidence for the mediational hypothesis that inaccurate forecasters with high scores on closure and simplicity maintained confidence in their world views by generating close-call counterfactuals and the off-on-timing defense.

\section{Discussion}

It is arguably unfair to criticize our respondents for their lackluster predictive performance. World politics may indeed pose an insurmountably indeterminate prediction task in which one quickly reaches the point of diminishing marginal returns for increments in expertise (cf. Almond \& Genco, 1977; Jervis, 1992). From this standpoint, it may simply be impossible to perform consistently better than chance in anticipating many political and economic events.

It seems reasonable, however, to note some other potential judgmental failings revealed by the data. First, the current study replicates the already well-replicated finding of overconfidence. The confidence that experts initially expressed in their forecasts substantially exceeded their objective accuracy scores. Indeed, expertise seemed most strongly associated with hubris. Experts venturing predictions in their domains of specialization differed from experts trespassing into alien domains primarily in the confidence they expressed in their predictions, not in their ability to foresee trends.

Second, experts who made inaccurate predictions managed to retain almost as much confidence in their world view after learning the outcomes as did experts who made accurate predictions. Political forecasting seems, by the standard of Einhorn and Hogarth (1981), to qualify as an outcome-irrelevant learning situation-no matter what happens, people feel no need to modify their preconceptions. The path-dependent nature of world politics - no one can justifably claim to know for sure what would have happened if hypothesized causes had taken on different values - apparently gives license to theory-driven thinkers to posit whatever outcomes they find convenient in the imaginary control conditions of history.

Third, there are consequential individual differences in cognitive style that moderate how experts respond to disconfirmation. High closure and simplicity respondents who assigned relatively high ex ante subjective probabilities to scenarios that did not occur were especially likely to endorse the trilogy of beliefsystem defense tactics (close-call counterfactuals, off on timing, and trivialization) and to express ex post confidence in the correctness of the world view that spawned the original forecast. Indeed, inaccurate high closure and simplicity respondents were (nonsignificantly) more likely to think they were right about the fundamental forces at work than were accurate forecasters.

Still, academic observers should pause before issuing normative judgments. Unlike laboratory tasks that offer well-defined normative bechmarks for labeling effects as errors or biases (assuming participants accept the experimenter's definition of the task), there are formidable conceptual and empirical obstacles to drawing conclusions about irrationality in complex field settings of the sort investigated here. Although it may be tempting to disparage high closure and simplicity respondents for their "imperviousness" to evidence, the blunt truth of the matter is that when we succumb to this temptation, we are being epistemologically presumptuous. Relative to the experts studied here, psychologists probably possess no more insight, and certainly command fewer facts, about whether Soviet Communists almost succeeded in their bid to cling to power or whether South Africa almost slipped into a bloody civil war. And psychologists are unlikely to have any special insights into whether Canada might still disintegrate or South Africa might yet be plunged into an interracial and tribal civil war. In short, the belief-system defenses invoked by many experts (especially those high on closure and simplicity) may be defensible on both philosophical and empirical grounds.

\section{General Discussion}

Taken together, the two studies tie together three previously unrelated lines of research: work on cognitive style, work on counterfactual reasoning, and work on the mechanisms underlying belief perseverance in expert cognition. Respondents rejected close-call counterfactuals that challenged causal schemata for understanding the past and embraced close-call counterfactuals that protected conditional forecasts from refutation. Moreover, experts who scored high on the multimethod composite measure of cognitive style and closure and simplicity were especially likely to display this pattern of judgment. Cognitive closure and simplicity amplified rejection of close-call counterfactuals that highlighted indeterminacy in the distant past but amplified acceptance of close-call counterfactuals that cushioned forecasts from disconfirmation.

The current studies also qualify as methodologically innovative in some key respects. Participants were not the proverbial bored undergraduates; rather, they were highly trained specialists who were judging scenarios (running either backward or forward in time) that engaged their interest and were often quite central to their avowed professional domains of expertise. It is thus possible to escape many of the objections that have been raised to traditional laboratory demonstrations of error and bias (cf. Funder, 1987; Kruglanski, 1989). The data revealed, for example, that experts differed from nonexperts in the confidence they attached to domain-relevant forecasts but not in the accuracy of those forecasts - a result that would lose much of its impact had the demonstration involved simulated, rather than actual political events. But the benefits of a naturalistic and longitudinal research design-assessing cognitive strategies in context over substantial stretches of time - are purchased at a steep price. Most laboratory paradigms give well-defined standards for declaring when people have "gone too far" and fallen prey to belief perseverance. That normative precision is lost here. As noted earlier, there is potential for endless argument over whether experts were too quick to reject close-call counterfactuals that undermined favorite covering laws and over whether experts were too quick to embrace close-call counterfactuals that protected conditional forecasts of events that failed to occur. Indeed, one could even argue that normative 
ambiguity is the critical defining feature of historical judgment-ambiguity that is the inevitable result of the complex path dependency of human affairs and the powerful passions activated by contests over whose interpretations will prevail of what would have happened or might yet happen (March \& Olsen, in press; Tetlock, 1994, 1998).

The current study also sheds new light on the burgeoning literature on counterfactual cognition which has shown that what-if thoughts influence a wide range of outcomes, including emotions, coping strategies, attributions of causality and responsibility, and judgments of both victim compensation and punishment (Roese, 1997). The two studies reported here demonstrate that people also use counterfactual thoughts to bolster their belief systems, both by protecting prior understandings of the past and by cushioning conditional forecasts from refutation. Experts' counterfactual reasoning was largely theory driven. But it was not exclusively so and the data contain hints of when theory-driven versus data-driven processing will dominate. Data-driven counterfactual reasoning is more likely when people judge the mutability of historical antecedents and when their preconceptions are not disturbed by the consequences that might flow from altering those antecedents. By contrast, theory-driven counterfactual reasoning is more likely when experts with welldeveloped preconceptions are called on to judge the mutability of the historical antecedents that may have far-reaching and dissonant consequences.

In closing, it is worth considering the broader conceptual implications of the findings. Since Thucydides ( 400 B.C.E./ 1972), historians have grappled with a tension between two compelling ideas: (a) The course of events often seems to be dictated by chance and (2) events often seem to possess their own inexorable logic. Most experts in our samples alternated between these conflicting ontological intuitions. Most accepted that small-scale, stochastic events can be consequential but simultaneously believed that individual agents work within the constraints of powerful societal forces. Individual differences emerged with respect to the types of constraints that experts acknowledged and the degree to which these constraints were seen as constraining.

In this regard, it is instructive to think of political cognitive styles within the framework of Peabody plots that allow us to disentangle the diverse denotative and connotative meanings that observers can attach to individual differences in information processing (cf. Peabody, 1967; Tetlock, Peterson, \& Berry, 1993; Tetlock \& Tyler, 1996). There are four logical possibilities:

1. The positive value spin on the low need for closure and the high complexity end of the continuum is that such thinkers are imaginative, intellectually flexible, open-minded, and selfcritical. Here one could praise these individuals for their willingness to concede the fallibility of their understanding of the past (acknowledging lacunae in favorite historical generalizations) as well as the shortcomings in their predictions of the future (their openness to the possibility that they were wrong rather than "almost right").

2. The positive value spin on the high need for closure and the low complexity end of the continuum is that such thinkers are intellectually disciplined, decisive, and determined to maintain an internally coherent point of view. Here one could praise these individuals for their taut, well-integrated belief systems and their principled commitment to defending their theoretical point of view - a point of view that may yet be borne out by subsequent events.

3. The negative value spin on low need for closure and high complexity is that such thinkers are intellectually undisciplined, inconsistent, and self-contradictory. They fail to recognize the tensions between the causal generalizations that they endorse at one moment and the historical counterfactuals to which they grant plausibility at the next. They also fail to mount spirited defenses of conditional forecasts that may yet turn out to be on the mark.

4. The negative value spin on high need for closure and low complexity is that such thinkers are rigid, dogmatic, and closedminded. They are prisoners of their preconceptions - unable or unwilling to concede that their understanding of the past is riddled with imperfections and their predictions of the future systematically off the mark.

Which characterization one prefers is itself likely to be a function of both one's cognitive style and philosophy of history.

\section{References}

Abelson, R. (1968). Psychological implication. In I. R. Abelson, E. Aronson, W. J. McGuire, T. M. Newcomb, M. J. Rosenberg, \& P. H. Tannenbaum (Eds.), Theories of cognitive consistency: A source book (pp. 112-139). Chicago: Rand McNally.

Almond, G., \& Genco, T. (1977). Clouds, clocks, and the study of politics. World Politics, 3, 489-522.

Einhorn, H., \& Hogarth, R. (1981). Behavioral decision theory: Processes of judgment and choice. Annual Review of Psychology, 31, 53-88.

Fearon, J. (1991). Counterfactuals and hypothesis testing in political science. World Politics, 43, 169-195.

Feist, G. J. (1994). Personality and working style predictors of integrative complexity: A study of scientists' thinking about research and teaching. Journal of Personality and Social Psychology, 67, 474484.

Ferguson, N. (1997). Virtual history. London: Picador.

Fischhoff, B. (1975). Hindsight is not equal to foresight: The effect of outcome knowledge on judgment under uncertainty. Joumal of Experimental Psychology, 104, 288-299.

Fischhoff, B. (1982). Debiasing. In D. Kahneman, P. Slovic, \& A. Tversky (Eds.), Judgment under uncertainty (pp. 237-262). Cambridge, England: Cambridge University Press.

Funder, D. C. (1987). Errors and mistakes: Evaluating the accuracy of social judgement. Psychological Bulletin, 101, 75-90.

Hawkins, S., \& Hastie, R. (1990). Hindsight: Biased judgment of past events after outcomes are known. Psychological Bulletin, 107, 311327.

Hempel, C. (1965). Aspects of scientific explanation, and other essays in the philosophy of science. New York: Free Press.

Jervis, R. (1992). The future of international politics: Will it resemble the past? International Security, 16, 39-73.

Johnson, M. K., \& Sherman, S. J. (1990). Constructing and reconstructing the past and the future in the present. In E. T. Higgins \& R. M. Sorrentino (Eds.), Handbook of motivation and cognition: Foundations of social behavior (Vol. 2, pp. 482-526). New York: Guilford Press.

Kahneman, D., \& Miller, D. (1986). Norm theory: Comparing reality to its alternatives. Psychological Review, 93, 136-153.

Kahneman, D., \& Varey, C. (1990). Propensities and counterfactuals: The loser that almost won. Journal of Personality and Social Psychology, 59, 1101-1110. 
Kruglanski, A. W. (1989). The psychology of being "right": The problem of accuracy in social perception and cognition. Psychological Bulletin, 106, 395-409.

Kruglanski, A. W., \& Webster, D. M. (1996). Motivated closing of the mind: "Seizing" and "freezing." Psychological Review, 103, 263268.

Layne, C. (1993). The unipolar illusion. International Security, 17, 5SI.

Loevinger, J. (1976). Ego development: Conceptions and theories. San Francisco: Jossey-Bass.

March, J. G., \& Olsen, J. P. (in press). The institutional dynamics of international political orders. International Organization.

McGuire, W. J. (1968). Theory of the structure of human thought. In R. Abelson, E. Aronson, W. J. McGuire, T. M. Newcomb, M. J. Rosenberg, \& P. H. Tannenbaum (Eds.), Theories of cognitive consistency: A sourcebook (pp. 140-162). Chicago: Rand McNally.

Peabody, D. (1967). Trait inferences: Evaluative and descriptive aspects. Journal of Personality and Social Psychology, 7, 1-18.

Roese, N. J. (1997). Counterfactual thinking. Psychological Bulletin, $121,133-148$.

Roese, N. J., \& Olson, J. (1995). Counterfactual thinking: A critical overview. In N. J. Roese \& J. Olson (Eds.), What might have been: The social psychology of counterfactual thinking (pp. 1-49). Hillsdale, NJ: Erlbaum.

Roese, N. J., \& Olson, J. (1996). Counterfactuals, causal attributions, and the hindsight bias: A conceptual integration. Journal of Experimental Social Psychology, 32, 197-227.

Streufert, S. (1997). Complexity: An integration of theories. Journal of Applied Social Psychology, 27, 2068-2096.

Suedfeld, P. (1983). Authoritarian leadership: A cognitive-interactionist view. In J. Held (Ed.), The cult of power: Dictators in the twentieth century (pp. 121-149). New York: Columbia University Press.

Suedfeld, P. (1992). Cognitive managers and their critics. Political Psychology, 13, 435-454.

Tetlock, P. E. (1988). Structure and function in political belief systems. In A. G. Greenwald \& A. Pratkanis (Eds.), Attitude structure and function (pp. 129-151). Hillsdale, NJ: Erlbaum.

Tetlock, P. E. (1992a). Cognitive structural analysis of political rhetoric: Methodological and theoretical issues. In S. Iyengar \& W. J. McGuire (Eds.), Political psychology: A reader. Durham, NC: Duke University Press.

Tetlock, P. E. (1992b). Good judgment in world politics: Three psychological perspectives. Political Psychology, 13, 517-540.
Tetlock, P. E. (1994, July). Good judgment in world politics: Who gets what right, when, and why? Invited presentation at annual meeting of American Psychological Society, Washington, DC.

Tetlock, P. E. (1994). Political psychology or politicized psychology: Is the road to scientific hell paved with good moral intentions? Political Psychology, 15, 509-530.

Tetlock, P. E. (1997). Theory-driven reasoning about possible pasts and probable futures: Are we prisoners of our preconceptions? Unpublished manuscript, Ohio State University, Columbus.

Tetlock, P. E. (1998). Social psychology and world politics. In S. Fiske, D. Gilbert, \& G. Lindzey (Eds.), Handbook of social psychology (4th ed., pp. 868-912). New York: McGraw-Hill.

Tetlock, P. E., Armor, D., \& Peterson, R. (1994). The slavery debate in antebellum America: Cognitive style, value conflict, and the limits of compromise. Joumal of Personality and Social Psychology, 66, 115126.

Tetlock, P. E., \& Belkin, A. (1996). Counterfactual thought experiments in world politics: Logical, methodological, and psychological perspectives. Princeton, NJ: Princeton University Press.

Tetlock, P. E., McGuire, C., \& Mitchell, P. G. (1991). Psychological perspectives on nuclear deterrence. Annual Review of Psychology, 42, $239-276$.

Tetlock, P. E., Peterson, R. S., \& Berry, J. M. (1993). Flattering and unflattering personality portraits of integratively simple and complex managers. Journal of Personality and Social Psychology, 64, 500511.

Tetlock, P. E., \& Tyler, A. (1996). Winston Churchill's cognitive and rhetorical style: The debates over Nazi intentions and self-government for India. Political Psychology, 17, 149-170.

Thucydides. (1972). The Peloponnesian War (R. Warner, Trans.). Baltimore: Penguin Books. (Original work published circa 400 B.C.)

Vannoy, J. S. (1965). Generality of cognitive complexity-simplicity as a personality construct. Journal of Personality and Social Psychology, $2,385-396$.

Vasquez, J. A. (1997). The realist paradigm and degenerative versus progressive research programs: An appraisal of neotraditional research on Waltz's balancing proposition. American Political Science Review, 91, 899-913.

Waltz, K. N. (1979). Theory of international politics. Reading, MA: Addison-Wesley.

Received October 16, 1997

Revision received March 15, 1998

Accepted March 25, 1998 